This item was submitted to Loughborough's Research Repository by the author.

Items in Figshare are protected by copyright, with all rights reserved, unless otherwise indicated.

\title{
The effect of Nd substitution on the electrical properties of Bi3NbTiO9
}

\section{Aurivillius phase ceramics}

PLEASE CITE THE PUBLISHED VERSION

http://dx.doi.org/10.1063/1.3205006

\section{PUBLISHER}

(c) American Institute of Physics

\section{VERSION}

VoR (Version of Record)

\section{PUBLISHER STATEMENT}

This work is made available according to the conditions of the Creative Commons Attribution-NonCommercialNoDerivatives 4.0 International (CC BY-NC-ND 4.0) licence. Full details of this licence are available at: https://creativecommons.org/licenses/by-nc-nd/4.0/

\section{LICENCE}

CC BY-NC-ND 4.0

\section{REPOSITORY RECORD}

Zhang, Hongtao, Haixue Yang, and Michael J. Reece. 2015. "The Effect of Nd Substitution on the Electrical Properties of Bi3nbtio9 Aurivillius Phase Ceramics”. figshare. https://hdl.handle.net/2134/17759. 


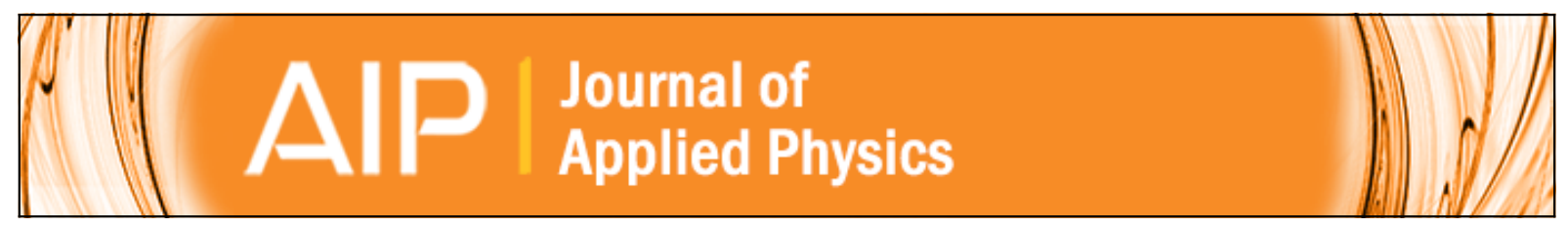

The effect of $\mathrm{Nd}$ substitution on the electrical properties of $\mathrm{Bi} 3 \mathrm{NbTiO} 9$ Aurivillius phase ceramics

Hongtao Zhang, Haixue Yan, and Michael J. Reece

Citation: Journal of Applied Physics 106, 044106 (2009); doi: 10.1063/1.3205006

View online: http://dx.doi.org/10.1063/1.3205006

View Table of Contents: http://scitation.aip.org/content/aip/journal/jap/106/4?ver=pdfcov

Published by the AIP Publishing

\section{Articles you may be interested in}

Enhanced ferroelectricity, piezoelectricity, and ferromagnetism in Nd-modified BiFeO3-BaTiO3 lead-free ceramics

J. Appl. Phys. 116, 184101 (2014); 10.1063/1.4901198

Structural and optical properties of rare earth-doped (Ba0.77Ca0.23)1-x(Sm, Nd, $\mathrm{Pr}, \mathrm{Yb}) \times \mathrm{TiO} 3$

J. Appl. Phys. 109, 124102 (2011); 10.1063/1.3594710

Effect of lattice occupation behavior of $\mathrm{Li}+$ cations on microstructure and electrical properties of

(Bi1/2Na1/2)TiO3-based lead-free piezoceramics

J. Appl. Phys. 109, 054102 (2011); 10.1063/1.3555598

High temperature properties of $\mathrm{BiScO} 3-\mathrm{PbTiO} 3$ piezoelectric ceramics

J. Appl. Phys. 106, 014102 (2009); 10.1063/1.3158542

Phase structures and electrical properties of new lead-free ( $\mathrm{Na} 0.5 \mathrm{~K} 0.5$ ) Nb O $3-(\mathrm{Bi} 0.5 \mathrm{Na} 0.5$ ) Ti O 3 ceramics

Appl. Phys. Lett. 90, 092904 (2007); 10.1063/1.2710768

\section{MIT LINCOLN} LABORATORY CAREERS

Discover the satisfaction of innovation and service to the nation
- Space Control

- Air \& Missile Defense

- Communications Systems \& Cyber Security

- Intelligence, Surveillance and

Reconnaissance Systems

- Advanced
Electronics
- Tactical Systems
- Homeland
Protection
- Air Traffic Control

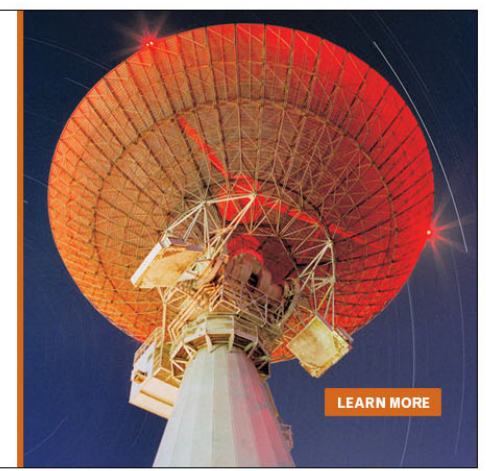




\title{
The effect of $\mathrm{Nd}$ substitution on the electrical properties of $\mathrm{Bi}_{3} \mathrm{NbTiO}_{9}$ Aurivillius phase ceramics
}

\author{
Hongtao Zhang, ${ }^{1}$ Haixue Yan, ${ }^{1,2}$ and Michael J. Reece ${ }^{1,2, a)}$ \\ ${ }^{1}$ School of Engineering and Materials Science, Queen Mary University of London, London E1 4NS, United \\ Kingdom \\ ${ }^{2}$ Nanoforce Technology Ltd., London E1 4NS, United Kingdom
}

(Received 31 March 2009; accepted 22 July 2009; published online 26 August 2009)

\begin{abstract}
The effect of Nd substitution on the microstructures and electrical properties of Aurivillius phase ferroelectric $\mathrm{Bi}_{3} \mathrm{NbTiO}_{9}$-based ceramics has been studied. All of the $\mathrm{Bi}_{3-x} \mathrm{Nd}_{x} \mathrm{NbTiO}_{9}(0 \leq x \leq 1)$ ceramics are ferroelectrics. The Curie point $T_{C}$ decreased with increasing $\mathrm{Nd}$ doping content $x$. The $\mathrm{Bi}_{3-x} \mathrm{Nd}_{x} \mathrm{NbTiO}_{9}$ ceramics exhibited a sharp ferroelectric-paraelectric phase transition at small $x$ values $(x \leq 0.6)$, whereas a diffuse phase transition was observed at higher $x$ values $(x \geq 0.8)$. Both the piezoelectric constant $d_{33}$ and the dc electrical resistivity of $\mathrm{Bi}_{3} \mathrm{NbTiO}_{9}$ ceramics were greatly enhanced by $\mathrm{Nd}$ substitution on the $A$ sites. The improved properties can be attributed to the fact that $\mathrm{Nd}$ substitution depressed the generation of oxygen vacancies. A combination of high $d_{33}$ values, high resistivity, and high $T_{C}$ points $\left(>700{ }^{\circ} \mathrm{C}\right)$ suggests that the $\mathrm{Bi}_{3-x} \mathrm{Nd}_{x} \mathrm{NbTiO}_{9}$ ceramics with $x \leq 0.6$ could be good candidates for high-temperature piezoelectric applications. (C) 2009 American Institute of Physics. [DOI: 10.1063/1.3205006]
\end{abstract}

\section{INTRODUCTION}

Bismuth layer-structured ferroelectrics (BLSFs), which belong to the Aurivillius family with the general formula $\left(\mathrm{Bi}_{2} \mathrm{O}_{2}\right)^{2+}\left(\mathrm{A}_{m-1} \mathrm{~B}_{m} \mathrm{O}_{3 m+1}\right)^{2-}$, are important lead-free ferroelectrics. ${ }^{1}$ The structure of these compounds can be described as pseudoperovskite $\left(\mathrm{A}_{m-1} \mathrm{~B}_{m} \mathrm{O}_{3 m+1}\right)^{2-}$ slabs separated by $\left(\mathrm{Bi}_{2} \mathrm{O}_{2}\right)^{2+}$ layers along the crystallographic $c$-axis. The 12-coordinated $A$ site can be occupied by mono-, di-, or trivalent ions, while the octahedral-coordinated $B$ site can be occupied by tri-, tetra-, penta-, or hexavalent ions. The number of octahedra along the $c$-axis between two neighboring $\left(\mathrm{Bi}_{2} \mathrm{O}_{2}\right)^{2+}$ layers is indicated by $m .^{2}$ In recent years, BLSFs have been given much attention because some materials, such as $\mathrm{SrBi}_{2} \mathrm{Ta}_{2} \mathrm{O}_{9}$ (Ref. 3) and $\mathrm{Bi}_{3.25} \mathrm{La}_{0.75} \mathrm{Ti}_{3} \mathrm{O}_{12}$, are excellent candidates for nonvolatile ferroelectric random access memory (FRAM) applications. BLSFs are also good candidates for high-temperature piezoelectric applications because of their higher Curie points $\left(T_{C}\right){ }^{5}$

The origin of ferroelectricity in BLSFs is the displacement of the $A$ site cations of the perovskite block with cooperative tilting of the $\mathrm{BO}_{6}$ octahedra. ${ }^{6}$ The piezoelectric activity of BLSFs is low because the rotation of the spontaneous polarization is restricted to the $a-b$ plane. $^{7}$ Therefore, an improvement of the piezoelectric activity of BLSFs by doping without producing a large decrease in their high $T_{C}$ is of great interest for high-temperature piezoelectric applications. It is established that the distortions of the octahedra can be largely enhanced by the lanthanide substitution on the $A$ sites in the pseudoperovskite layer. ${ }^{8}$ Lanthanide cation modified BLSFs were first studied in the pioneering work of Wolfe and Newnham. ${ }^{9}$ They found that the Curie points of $\mathrm{Bi}_{4} \mathrm{Ti}_{3} \mathrm{O}_{12}$ decreased with increasing lanthanide doping. Lanthanum substituted bismuth titanate $\left(\mathrm{Bi}_{3.25} \mathrm{La}_{0.75} \mathrm{Ti}_{3} \mathrm{O}_{12}\right)$ thin

${ }^{a)}$ Electronic mail: m.j.reece@qmul.ac.uk. films were reported to be promising candidates for nonvolatile FRAM due to their large remanent polarization $\left(P_{r}\right)$ and excellent fatigue resistance. ${ }^{4}$ It is expected that the substitution on the $A$ sites by other lanthanides with smaller ionic radius than that of $\mathrm{Bi}$ or $\mathrm{La}$ can further improve the ferroelectric properties. $^{10}$ More recently, Kojima and co-workers ${ }^{8,10}$ and Chon and co-workers ${ }^{11,12}$ independently reported great improvement of $P_{r}$ and fatigue resistance in Nd-doped $\mathrm{Bi}_{4} \mathrm{Ti}_{3} \mathrm{O}_{12}$ thin films. The $P_{r}$ of (104)-oriented $\mathrm{Bi}_{3.54} \mathrm{Nd}_{0.46} \mathrm{Ti}_{3} \mathrm{O}_{12}$ epitaxial thin films grown by Kojima and co-workers ${ }^{8,10}$ with metalorganic chemical vapor deposition was $25 \mu \mathrm{C} / \mathrm{cm}^{2}$, which is comparable to that of commercially used lead zirconate titanate (PZT) films for nonvolatile FRAM application. They attributed the large $P_{r}$ of $\mathrm{Bi}_{3.54} \mathrm{Nd}_{0.46} \mathrm{Ti}_{3} \mathrm{O}_{12}$ films to a large tilting of $\mathrm{TiO}_{6}$ octahedra induced by the substitution of $\mathrm{Nd}^{3+}$, the ionic radius of which is smaller than that of $\mathrm{Bi}^{3+}$ and $\mathrm{La}^{3+}\left[r\left(\mathrm{Bi}^{3+}\right)=1.30 \AA{ }^{13}\right.$ $r\left(\mathrm{La}^{3+}\right)=1.36 \AA{ }^{14} \quad r\left(\mathrm{Nd}^{3+}\right)=1.27 \AA{ }^{14} \quad$ coordination number $=12]$. Chon and co-workers ${ }^{11,12}$ obtained high values of $P_{r}\left(2 P_{r}>100 \mu \mathrm{C} / \mathrm{cm}^{2}\right)$ in sol-gel derived, highly $c$-axis oriented $\mathrm{Bi}_{3.15} \mathrm{Nd}_{0.85} \mathrm{Ti}_{3} \mathrm{O}_{12}$ films. The authors suggested that this rather unexpected giant polarization resulted from the tilting of the polarization vector along the $c$-axis in the $\mathrm{Bi}_{3.15} \mathrm{Nd}_{0.85} \mathrm{Ti}_{3} \mathrm{O}_{12}$ unit cell. Accordingly, $\mathrm{Nd}$ as a potential additive for improving ferroelectric properties of BLSFs needs to be further investigated. $\mathrm{Bi}_{3} \mathrm{NbTiO}_{9}$ (BNTO) is a member of BLSFs with a much higher $T_{C}\left(>900{ }^{\circ} \mathrm{C}\right)$ than that of $\mathrm{Bi}_{4} \mathrm{Ti}_{3} \mathrm{O}_{12}\left(675^{\circ} \mathrm{C}\right) .{ }^{15}$ Based on the fact that the anisotropies of the lattice constants of the $a$ and $b$ axes decrease for $\mathrm{Bi}_{3-x} \mathrm{Sm}_{x} \mathrm{NbTiO}_{9}$ ceramics with increasing content of Sm substitution, Sugaya et al. ${ }^{16}$ predicted that the piezoelectric properties of $\mathrm{Ln}\left[\mathrm{Ln}=\mathrm{La}, \mathrm{Nd}, \mathrm{Sm}, r\left(\mathrm{Sm}^{3+}\right)\right.$ $=1.24 \AA$ (Ref. 14) and Gd, $r\left(\mathrm{Gd}^{3+}\right)=1.107 \AA$ (Ref. 14)]doped BNTO would decrease with increasing content of lan- 
thanide substitution. However, no study on the effect of $\mathrm{Nd}$ doping on the electrical properties of BNTO has been performed.

In the present study, the effect of $\mathrm{Nd}$ doping on the microstructures and electrical properties of BNTO has been systematically investigated with the aim of identifying the compositions with good properties for high-temperature piezoelectric application.

\section{EXPERIMENTAL}

Polycrystalline ceramic samples with the formula of $\mathrm{Bi}_{3-x} \mathrm{Nd}_{x} \mathrm{NbTiO}_{9}(\mathrm{BNNT}-x)$ where $x=0,0.2,0.4,0.6,0.8$, and 1.0 were prepared by conventional solid-state reaction sintering. The starting materials were $\mathrm{Bi}_{2} \mathrm{O}_{3}$ of $99.975 \%$ purity, $\mathrm{Nd}_{2} \mathrm{O}_{3}$ of $99.0 \%$ purity, $\mathrm{TiO}_{2}$ of $99.6 \%$ purity, and $\mathrm{Nb}_{2} \mathrm{O}_{5}$ of $99.5 \%$ purity. The stoichiometric mixtures of oxides were thoroughly milled for $24 \mathrm{~h}$ in a nylon pot. Then the mixed powder was calcined in air at $950{ }^{\circ} \mathrm{C}$ for $4 \mathrm{~h}$. After milling for $24 \mathrm{~h}$, the calcined powders were pressed into pellets. The pressed samples were sintered at $1150-1200{ }^{\circ} \mathrm{C}$ for $1 \mathrm{~h}$ in air.

The phase content of the BNNT $-x$ calcined powders was determined using $\mathrm{x}$-ray diffraction (XRD) (Siemens D5000) with $\mathrm{Cu} K \alpha$ radiation. Electrodes for hightemperature electrical property measurements were fabricated with platinum paste (Gwent Electronic Materials Ltd., C2011004D5). The temperature dependence of the dielectric constants and losses were measured at different frequencies using an $L C R$ meter (Agilent 4284A). The ferroelectric $P-E$ hysteresis loops were measured at $200{ }^{\circ} \mathrm{C}$ and $10 \mathrm{~Hz}$ using a ferroelectric hysteresis measurement tester. ${ }^{5}$ The measurement procedure involved the application of triangular voltage waveforms with two complete cycles to the test samples. Samples for piezoelectric measurements were poled in silicone oil at $200{ }^{\circ} \mathrm{C}$ under dc electric field strengths from 8 to $11 \mathrm{kV} / \mathrm{mm}$ for $5-15$ min depending on their bulk conductivities. The piezoelectric constant $d_{33}$ was measured using a piezo- $d_{33}$ meter (ZJ-3B, Institute of Acoustics, Chinese Academic of Science, Beijing). A high resistance meter (Keithley 6517A) was used to measure the resistivity of each composition up to $T_{C}$ in a direct current circuit.

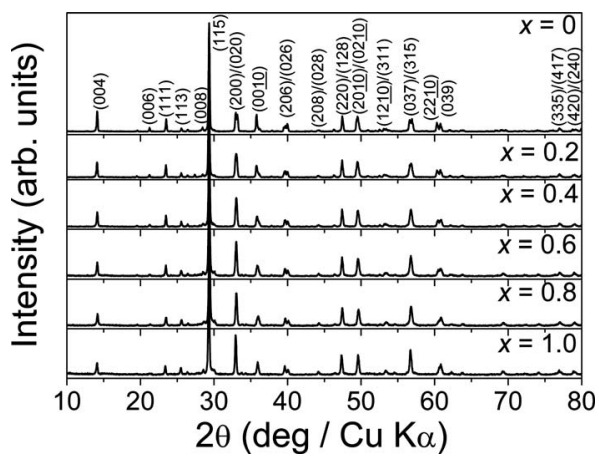

FIG. 1. XRD patterns of BNNT $-x$ calcined powders as a function of $x$.
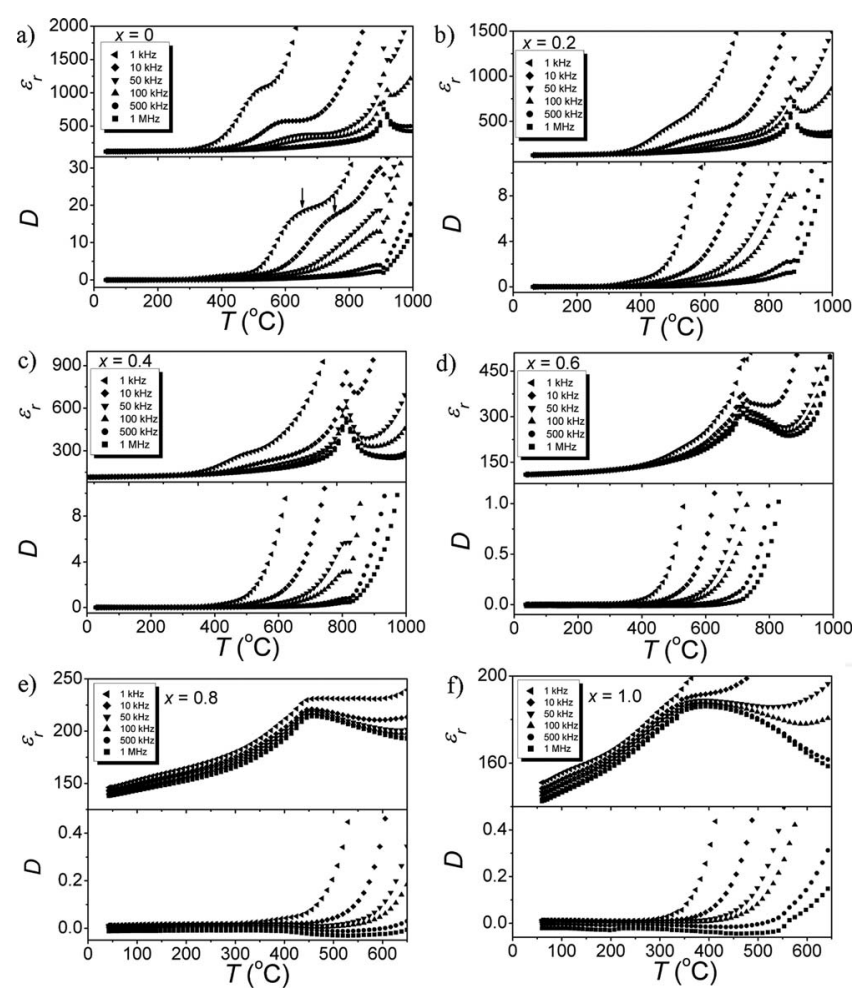

FIG. 2. Temperature dependence of dielectric constant $\varepsilon_{r}$ and loss factor $D$ for different $x$ values for BNNT $-x$ at different frequencies: (a) $x=0$, (b) $x$ $=0.2$, (c) $x=0.4$, (d) $x=0.6$, (e) $x=0.8$, and (f) $x=1.0$.

\section{RESULTS AND DISCUSSION}

Table I summarizes the optimized sintering temperatures, based on highest density, for the BNNT $-x$ ceramics that were studied.

\section{A. Crystal structure}

The XRD patterns for different BNNT $-x$ calcined powders are presented in Fig. 1. All samples exhibit a BLSF structure, which can be well indexed according to Ref. 17 for BNTO. The ceramics consisted of a single Aurivillius phase without detectable secondary phases within the sensitivity of the XRD equipment. The Aurivillius phase structure of BNTO can be maintained for a high doping content up to $x$

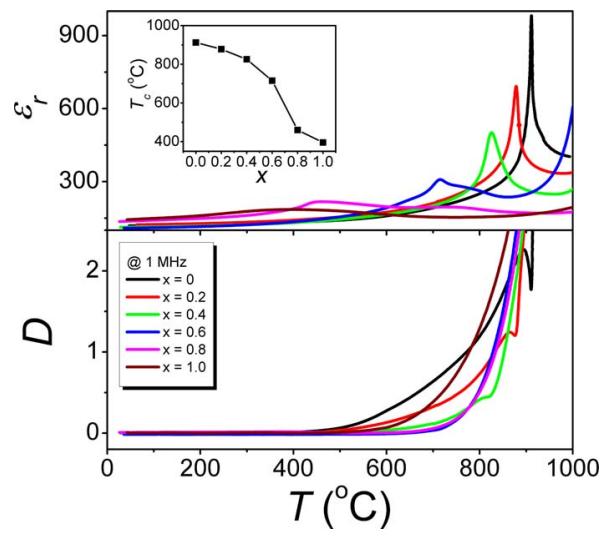

FIG. 3. (Color online) Temperature dependence of dielectric constants of BNNT $-x$ ceramics at $1 \mathrm{MHz}$. The inset shows the dependence of $T_{C}$ on Nd substitution content $x$. 

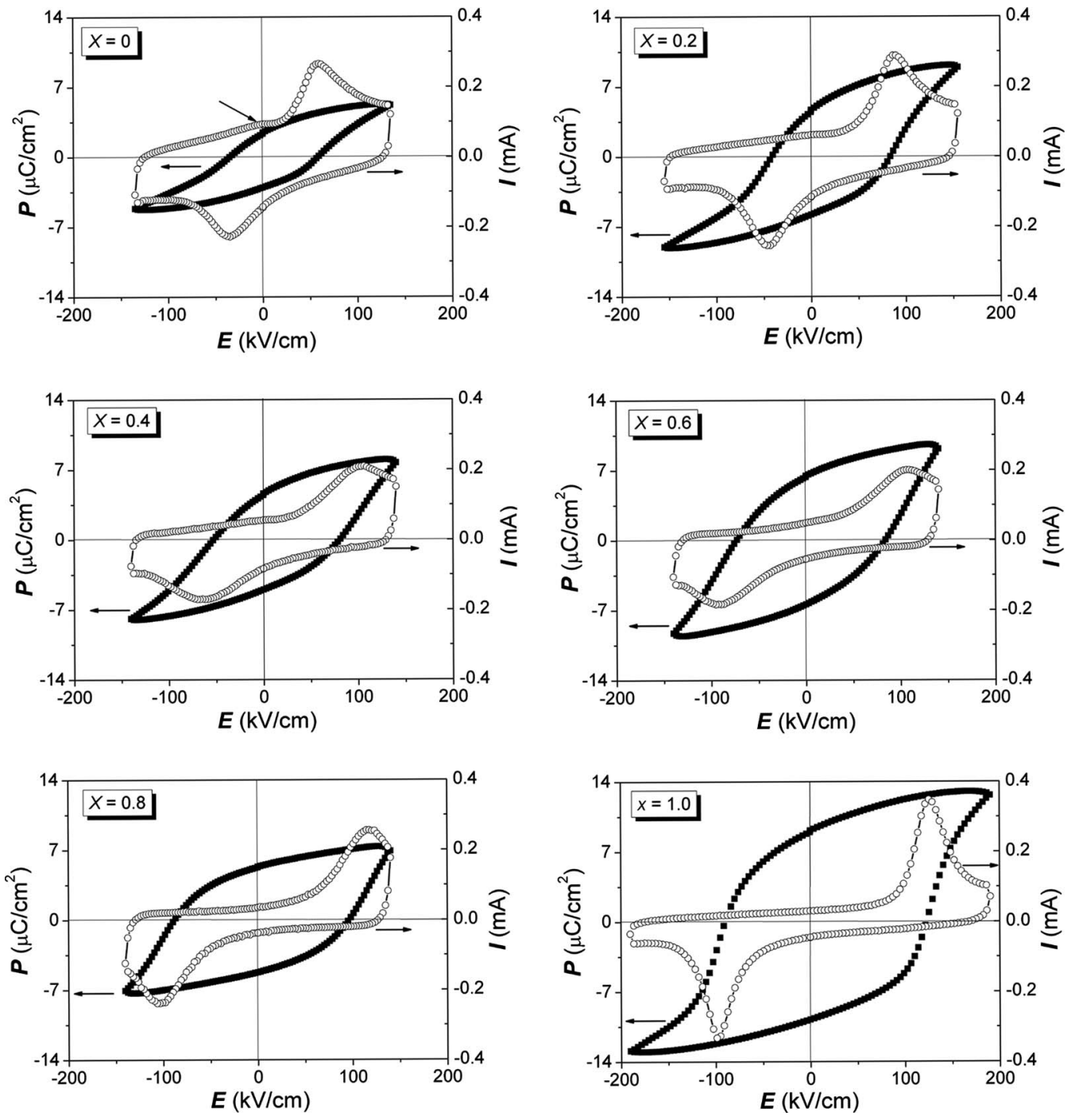

FIG. 4. $I-E$ and $P-E$ loops of BNNT $-x$ ceramics measured at $200{ }^{\circ} \mathrm{C}$ and $10 \mathrm{~Hz}$.

$=1.0$ because the valences of $\mathrm{Bi}$ and $\mathrm{Nd}$ are the same and the radii of $\mathrm{Bi}$ and $\mathrm{Nd}$ are very similar. Sugaya et al. ${ }^{16}$ also reported that the Aurivillius phase structure can be maintained without the appearance of a second phase for $x$ as large as 1.0 in the BNNT $-x$ system.

\section{B. Dielectric properties}

Figure 2 shows the temperature dependence of the dielectric constant $\varepsilon_{r}$ and loss factor $D$ at various $x$ values in the BNNT $-x$ system. BNTO $(x=0)$ has a ferroelectric to

TABLE I. Optimal sintering temperatures for the highest densities of the BNNT $-x$ ceramics (the relative density is shown in parentheses).

\begin{tabular}{lll}
\hline \hline$x$ & $\begin{array}{c}\text { Sintering temperature } \\
\left({ }^{\circ} \mathrm{C}\right)\end{array}$ & $\begin{array}{l}\text { Density } \\
\left(\mathrm{g} / \mathrm{cm}^{3}\right)\end{array}$ \\
\hline 0 & 1150 & $8.12(98.3 \%)$ \\
0.2 & 1180 & 8.04 \\
0.4 & 1200 & 7.95 \\
0.6 & 1200 & 7.91 \\
0.8 & 1200 & 7.76 \\
1.0 & 1200 & 7.62 \\
\hline \hline
\end{tabular}

paraelectric phase transition at $913^{\circ} \mathrm{C}$, as shown by the sharp frequency independent maximum of $\varepsilon_{r}$ and the associated minimum of loss [Fig. 2(a)]. The dielectric constants at low temperatures $\left(T<300{ }^{\circ} \mathrm{C}\right)$ were similar regardless of the frequency used for the measurements. Frequency dependent broad undulations of the dielectric constants were observed at higher temperatures $\left(400-800{ }^{\circ} \mathrm{C}\right)$, and the apparent dielectric constants increased dramatically with decreasing frequency. This suggests that there are other mechanisms contributed to the dielectric polarization at high temperatures. This is usually interpreted in terms of contributions to the polarization from point defect dipoles, possibly produced by oxygen vacancies. ${ }^{18}$ The formation of oxygen vacancies in BLSFs results from the fragility of the Bi-O bonds, ${ }^{19}$ which results in nominal valence states for bismuth lower than $3^{+}{ }^{20}$ An oxygen vacancy hopping mechanism is responsible for dielectric relaxation, which is therefore a thermally activated process and exponentially dependent on temperature. The losses increased with increasing temperature. A set of frequency dependent loss peaks can be found between 600 and $800{ }^{\circ} \mathrm{C}$, as indicated by the arrows in Fig. 2(a). The position of these loss peaks shifted to higher 
temperatures as the frequency increased. This loss behavior is consistent with dielectric relaxation induced by oxygen vacancy hopping. The frequency dependent loss peaks at high temperature cannot be observed because dc conduction losses dominate.

Compositions $x=0.2$ and $x=0.4$ showed similar behaviors to $x=0$ [Figs. 2(b) and 2(c)]. They had sharp dielectric constant peaks at the Curie point. The frequency dependent broad undulations of the dielectric constants below the transition temperature were not as obvious as those in BNTO $(x=0)$. Also, the frequency dependent loss peaks were not observed, which suggests that $\mathrm{Nd}$ doping decreases the generation of oxygen vacancies, as reported for $\mathrm{Nd}$-doped $\mathrm{Bi}_{4} \mathrm{Ti}_{3} \mathrm{O}_{12}$ ceramics ${ }^{21}$ and thin films. ${ }^{22} \mathrm{~A}$ decrease in oxygen vacancies in $\mathrm{Bi}_{4} \mathrm{Ti}_{3} \mathrm{O}_{12}$ by $\mathrm{Nd}$ doping is attributed to the fact that the orbital hybridization between the $\mathrm{Nd} 5 d$ and $\mathrm{O} 2 p$ states stabilizes oxygen ions in the perovskite layers. ${ }^{23}$ The frequency dependent broad undulations of the dielectric constant disappeared for the composition with $x=0.6$ [Fig. 2(d)]. The compositions with $x=0.8$ and $x=1.0$ exhibited broad dielectric constant peaks [Figs. 2(e) and 2(f)] with a relaxor like behavior. However, no temperature shift with increasing frequency of the $\varepsilon_{r}$ peak was observed within the error of the measurements. Raman spectra for $\mathrm{Bi}_{4} \mathrm{Ti}_{3} \mathrm{O}_{12}$ thin films ${ }^{24,25}$ and high resolution neutron powder diffraction for $\mathrm{SrBi}_{2} \mathrm{Ta}_{2} \mathrm{O}_{9}$ ceramics ${ }^{26}$ revealed that neodymium is selectively substituted on the $A$ sites in the pseudoperovskite layer for small neodymium substitution content. However, with further increasing neodymium content, neodymium is also incorporated into the $\left(\mathrm{Bi}_{2} \mathrm{O}_{2}\right)^{2+}$ layer. It is well known that the relaxor behavior or diffuse phase transition of BLSFs can be induced once cation disorder between the perovskite $A$ site cations and the bismuth cations in the $\left(\mathrm{Bi}_{2} \mathrm{O}_{2}\right)^{2+}$ layer occurs. ${ }^{26,27}$ Thus, the diffuse phase transition in the compositions $x=0.8$ and $x=1.0$ in the BNNT $-x$ system indicates the occurrence of cation disorder in the $\left(\mathrm{Bi}_{2} \mathrm{O}_{2}\right)^{2+}$ layer.

The comparison of the temperature dependence of the $\varepsilon_{r}$ and $D$ at $1 \mathrm{MHz}$ for the various $\mathrm{Nd}$ contents is shown in Fig. 3 . It can be seen that as the Nd doping content $x$ increased, the peak in the dielectric permittivity curve, which corresponded to the ferroelectric-paraelectric phase transition, gradually became broader. The maximum value of the peak of $\varepsilon_{r}$ decreased and the peak position moved to lower temperatures with increasing $x$. This indicates that $\mathrm{Nd}$ doping brings about a strong diffuse ferroelectric-paraelectric phase transition. The dielectric behaviors in the present BNNT $-x$ system are consistent with the studies on lanthanide doped BLSFs, such as $\mathrm{Nd}-\mathrm{Bi}_{3} \mathrm{TaTiO}_{9}(m=2),{ }^{28} \mathrm{Sm}$-BNTO $(m$ $=2),{ }^{16} \quad \mathrm{La}-\mathrm{Bi}_{4} \mathrm{Ti}_{3} \mathrm{O}_{12} \quad(m=3), \quad \mathrm{SrBi}_{4} \mathrm{Ti}_{4} \mathrm{O}_{15} \quad(m=4)$, and $\mathrm{Sr}_{2} \mathrm{Bi}_{4} \mathrm{Ti}_{5} \mathrm{O}_{18} \quad(m=5) .{ }^{27}$ Compared with BNTO $(x=0)$, the losses in the Nd-doped samples were reduced. The inset in Fig. 3 shows the dependence of the Curie points $T_{C}$ on $\mathrm{Nd}$ doping content $x . T_{C}$ decreased with increasing $x$, having two regions with different slopes. The boundary between the two regions corresponds to $x=0.6$. This $x$ value is considered to be the solubility limit of $\mathrm{Nd}$ element on the $A$ sites in the pseudoperovskite structure. ${ }^{24,28} \mathrm{~A}$ two slope region in the relationship between $T_{C}$ and lanthanide substitution content

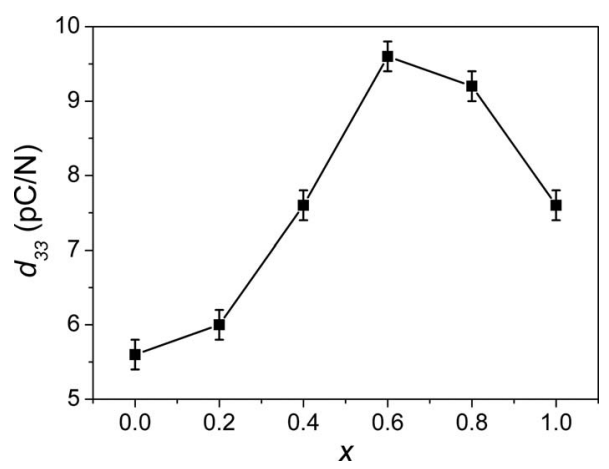

FIG. 5. Piezoelectric coefficient $d_{33}$ of BNNT $-x$ ceramics poled at $200{ }^{\circ} \mathrm{C}$.

was also reported in Nd- and La-doped $\mathrm{Bi}_{3} \mathrm{TaTiO}_{9}(m=2),{ }^{28}$ $\mathrm{Bi}_{4} \mathrm{Ti}_{3} \mathrm{O}_{12}(m=3),{ }^{24} \quad \mathrm{Na}_{0.5} \mathrm{Bi}_{4.5} \mathrm{Ti}_{4} \mathrm{O}_{15}(m=4), \quad$ and $\mathrm{PbBi}_{4} \mathrm{Ti}_{4} \mathrm{O}_{15}(m=4){ }^{29}$

\section{Ferroelectric and piezoelectric properties}

Figure 4 illustrates curves of $I-E$ and $P-E$ loops of BNNT $-x$ ceramics measured at $200{ }^{\circ} \mathrm{C}$ and $10 \mathrm{~Hz}$. The onset of ferroelectric domain switching, as indicated by current peaks in the $I-E$ curves, can be observed for all of the compositions in the BNNT $-x$ system. For BNTO $(x=0)$, besides high-field-induced current peaks at around the coercive field, a low-field-induced peak (identified by an arrow) on the positive $I$ side of the $I-E$ curve was also observed. The $P-E$ loops of BNTO exhibited an obvious asymmetry shift along the electrical field axis, which was probably produced by the pinning of the domain wall by the oxygen vacanciesimpurity complex dipole. ${ }^{30}$ Inspection of $I-E$ and $P-E$ loops for compositions $x=0.4-1.0$ reveals that the low-fieldinduced current peaks were not apparent and the $P-E$ loops became more symmetric with the increasing $\mathrm{Nd}$ doping content $x$. Consequently, the $P$-E results also demonstrate that $\mathrm{Nd}$ doping can decrease the oxygen vacancy concentration and minimize the detrimental effects from oxygen vacancies on polarization.

Figure 5 shows the dependence of piezoelectric coefficient $\left(d_{33}\right)$ on Nd doping content $x$. The nonzero $d_{33}$ values of all compositions with $x$ varying from 0 to 1.0 indicates that they are all ferroelectrics. The maximum $d_{33}$ occurred at $x=0.6$, which shows that the piezoelectric response of BNTO

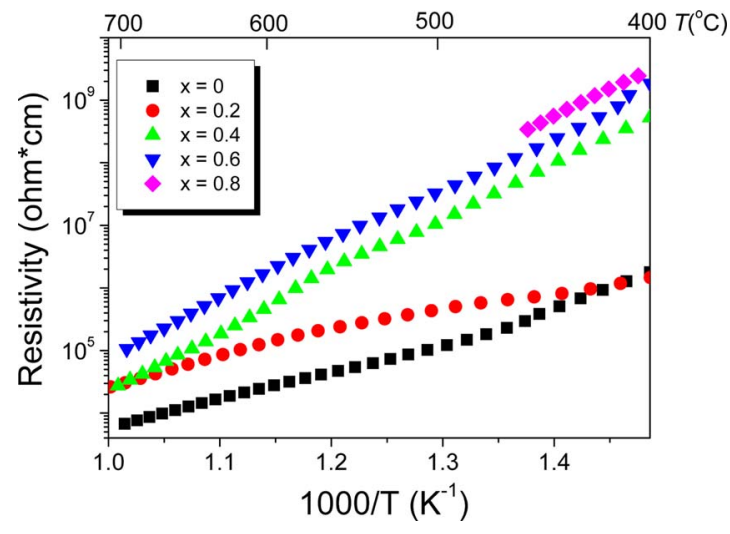

FIG. 6. (Color online) Arrhenius plots of de resistivity of BNNT $-x$ ceramics. 
TABLE II. Activation energies $E_{a}$ [from Eq. (1) and Fig. 6] of the BNNT $-x$ ceramics.

\begin{tabular}{lccccc}
\hline \hline & $x=0$ & $x=0.2$ & $x=0.4$ & $x=0.6$ & $x=0.8$ \\
\hline$E_{a}( \pm 0.1 \mathrm{eV})$ & 0.92 & 0.90 & 1.77 & 1.71 & 1.73 \\
\hline \hline
\end{tabular}

can be improved by $\mathrm{Nd}$ doping. The present results contradict the prediction made by Sugaya et al. ${ }^{16}$ that the piezoelectric properties of $\mathrm{Bi}_{3-x} \mathrm{Ln}_{x} \mathrm{TiNbO}_{9}$ would decrease with increasing content of lanthanide substitution.

\section{D. dc resistivity}

Electrical resistivity is one of the most important properties for BLSFs. High electrical resistivity allows higher poling field to be applied, which increases the piezoelectric properties that can be obtained. The electrical resistivities of all of the compositions except $x=1.0\left(T_{C}=395{ }^{\circ} \mathrm{C}\right)$ in the BNNT $-x$ system were measured above $400{ }^{\circ} \mathrm{C}$. Figure 6 shows the Arrhenius plots of the dc resistivity data. The resistivities of the compositions with $x=0.2-0.8$ were dramatically enhanced by $\mathrm{Nd}$ substitution. This is in good agreement with the observation that the dc conductivity of perovskite structured oxides containing titanium ions decreases with the decreasing concentrations of oxygen vacancies. ${ }^{31}$ The resistivity data follows the Arrhenius law quite well for all of the BNNT $-x$ ceramics $(x \leq 0.8)$. From the Arrhenius plots, the activation energies were calculated using the expression

$$
\rho=\rho_{0} \exp \left(E_{a} / k T\right)
$$

where $\rho$ is the resistivity, $\rho_{0}$ is a pre-exponential factor, $E_{a}$ is the activation energy, $k$ is Boltzmann's constant, and $T$ is the absolute temperature. The activation energies $E_{a}$ of all compositions are listed in Table II.

The activation energies $(\sim 0.90 \mathrm{eV})$ for the dc electrical conductivities of $x=0$ and 0.2 suggested an extrinsic conduction mechanism, which is most probably $p$-type conduction according to a previous study of the electrical conductivity of BNTO. ${ }^{32}$ With increasing Nd substitution up to $x=0.8$, the activation energy $E_{a}$ of BNTO ceramics increased from $\sim 0.90$ to $\sim 1.70 \mathrm{eV}$. This is associated with a change from extrinsic to intrinsic conductivity. It is well known that the intrinsic electronic conductivity activation energy is equal to half of the energy of the band gap $E_{g}$. Therefore, the band gap of BNNT $-x$ is $\sim 3.40 \mathrm{eV}$. This value is consistent with those of $\mathrm{Bi}_{4} \mathrm{Ti}_{3} \mathrm{O}_{12}, \mathrm{BaBi}_{4} \mathrm{Ti}_{4} \mathrm{O}_{15}$, and $\mathrm{BaTiO}_{3}$, which are all about $3.3 \mathrm{eV}$. The similarity of the band gap is due to the common $\mathrm{TiO}_{6}$ octahedra. ${ }^{33}$ The combination of high $d_{33}$ values, high resistivities, and high $T_{C}$ points $\left(>700{ }^{\circ} \mathrm{C}\right)$ suggests that the compositions with $x \leq 0.6$ could be good candidates for high-temperature piezoelectric application.

\section{CONCLUSION}

Ceramics with solid solutions in the $\mathrm{Bi}_{3-x} \mathrm{Nd}_{x} \mathrm{NbTiO}_{9}$ (BNNT $-x, 0 \leq x \leq 1)$ system were prepared and studied. The Curie point decreased with increasing $\mathrm{Nd}$ doping content $x$. The BNNT $-x$ ceramics exhibited a sharp ferroelectricparaelectric phase transition at small $\mathrm{Nd}$ content $(x \leq 0.6)$, whereas a diffuse phase transition was observed at higher $\mathrm{Nd}$ content $(x \geq 0.8)$. The gradual disappearance of the frequency dependent broad undulations of the dielectric constants and loss peaks below $T_{C}$ with increasing $\mathrm{Nd}$ content suggests that $\mathrm{Nd}$ doping can inhibit the generation of oxygen vacancies. All compositions $(x=0-1.0)$ are ferroelectrics, which was evidenced by their ferroelectric switching and piezoelectric properties. The piezoelectric coefficient $d_{33}$ and electrical resistivities of BNTO ceramics were greatly improved by $\mathrm{Nd}$ doping. The dc conduction of BNNT $-x$ at low $\mathrm{Nd}$ doping contents $(x \leq 0.2)$ above $400{ }^{\circ} \mathrm{C}$ is related to an extrinsic $p$-type mechanism. At higher $\mathrm{Nd}$ substitutions $(x$ $>0.2$ ), the conduction mechanism changed to intrinsic.

${ }^{1}$ B. Aurivillius, Ark. Kemi 1, 463 (1949).

${ }^{2}$ E. C. Subbarao, Phys. Rev. 122, 804 (1961).

${ }^{3}$ C. A. Araujo, J. D. Cuchiaro, L. D. McMillan, M. C. Scott, and J. F. Scott, Nature (London) 374, 627 (1995).

${ }^{4}$ B. H. Park, B. S. Kang, S. D. Bu, T. W. Noh, L. Lee, and W. Joe, Nature (London) 401, 682 (1999).

${ }^{5}$ H. Yan, H. Zhang, R. Ubic, M. J. Reece, J. Liu, Z. Shen, and Z. Zhang, Adv. Mater. (Weinheim, Ger.) 17, 1261 (2005).

${ }^{6}$ R. L. Withers, J. G. Thompson, and A. D. Rae, J. Solid State Chem. 94, 404 (1991).

${ }^{7}$ T. Takenaka and K. Sakata, J. Appl. Phys. 55, 1092 (1984).

${ }^{8}$ T. Kojima, T. Sakai, T. Watanabe, H. Funakubo, K. Saito, and M. Osada, Appl. Phys. Lett. 80, 2746 (2002).

${ }^{9}$ R. W. Wolfe and R. E. Newnham, J. Electrochem. Soc. 116, 832 (1969).

${ }^{10}$ T. Kojima, T. Watanabe, H. Funakubo, K. Saito, M. Osada, and M. Kakihana, J. Appl. Phys. 93, 1707 (2003).

${ }^{11}$ U. Chon, H. M. Jang, M. G. Kim, and C. H. Chang, Phys. Rev. Lett. 89, 087601 (2002).

${ }^{12}$ U. Chon, J. S. Shim, and H. M. Jang, Solid State Commun. 129, 465 (2004).

${ }^{13}$ D. Y. Suárez, I. M. Reaney, and W. E. Lee, J. Mater. Res. 16, 3139 (2001).

${ }^{14}$ R. D. Shannon, Crystallogr., Sect. A: Cryst. Phys., Diffr., Theor. Gen. Crystallogr. 32, 751 (1976).

${ }^{15}$ H. X. Yan, H. T. Zhang, Z. Zhang, R. Ubic, and M. J. Reece, J. Eur. Ceram. Soc. 26, 2785 (2006).

${ }^{16}$ Y. Sugaya, K. Shoji, and K. Sakata, Jpn. J. Appl. Phys., Part 1 42, 6086 (2003).

${ }^{17}$ JCPDS Card No. 72-1018.

${ }^{18}$ H. S. Shulman, D. Damjanovic, and N. Setter, J. Am. Ceram. Soc. 83, 528 (2000).

${ }^{19}$ M.-W. Chu, M. Ganne, M. T. Caldes, E. Gautier, and L. Brohan, Phys. Rev. B 68, 014102 (2003).

${ }^{20}$ Č. Jovalekić, M. Pavlović, P. Osmokrović, and Lj. Atanasoska, Appl. Phys. Lett. 72, 1051 (1998).

${ }^{21}$ W. Li, A. Chen, X. Lu, and J. Zhu, J. Appl. Phys. 98, 024109 (2005).

${ }^{22}$ S. T. Zhang, X. J. Zhang, H. W. Cheng, Y. F. Chen, Z. G. Liu, N. B. Min, X. B. Hu, and J. Y. Wang, Appl. Phys. Lett. 83, 4378 (2003).

${ }^{23}$ T. Goto, Y. Noguchi, M. Soga, and M. Miyayama, Mater. Res. Bull. 40, 1044 (2005).

${ }^{24}$ T. Watanabe, H. Funakubo, M. Osada, H. Uchida, and I. Okada, J. Appl. Phys. 98, 024110 (2005).

${ }^{25}$ R. E. Melgarejo, M. S. Tomar, S. Bhaskar, P. S. Dobal, and R. S. Katiyar, Appl. Phys. Lett. 81, 2611 (2002).

${ }^{26}$ Y. Noguchi, M. Miyayama, K. Oikawa, T. Kamiyama, M. Osada, and M. Kakihana, Jpn. J. Appl. Phys., Part 1 41, 7062 (2002).

${ }^{27}$ X. B. Chen, R. Hui, J. Zhu, W. P. Lu, and X. Y. Mao, J. Appl. Phys. 96, 5697 (2004).

${ }^{28}$ M. Suzuki, H. Nagata, J. Ohara, H. Funakubo, and T. Takenaka, Jpn. J. Appl. Phys., Part 1 42, 6090 (2003).

${ }^{29}$ T. Takenaka and K. Sakata, Ferroelectrics 38, 769 (1981).

${ }^{30}$ Q. Tan and D. Viehland, J. Am. Ceram. Soc. 81, 328 (1998).

${ }^{31}$ O. Bidault, P. Goux, M. Kchikech, M. Belkaoumi, and M. Maglione, Phys. Rev. B 49, 7868 (1994).

${ }^{32}$ Z. Zhou, X. Dong, H. Yan, H. Chen, and C. Mao, J. Appl. Phys. 100, 044112 (2006).

${ }^{33}$ S. Ehara, K. Muramatsu, M. Shimazu, J. Tanaka, M. Tsukioka, Y. Mori, T. Hattori, and H. Tamura, Jpn. J. Appl. Phys., Part 1 20, 877 (1981). 